\title{
O TRABALHO DOCENTE NA EDUCAÇÃO INFANTIL
}

\author{
Emília Peixoto Vieira ${ }^{1}$ \\ Frédéric André Robert Vaillant ${ }^{2}$
}

\begin{abstract}
RESUMO: Este artigo analisa o que significa o trabalho docente na educação infantil, ligando nossas análises teóricas aos desafios postos a esta etapa da educação diante da conjuntura brasileira. Utilizamos como instrumentos para coleta de informações as leituras no grupo de pesquisa, a inserção no curso de extensão, em diálogo com as coordenadoras, e a pesquisa em andamento nos 28 municípios do Sul da Bahia. 0 estudo da educação infantil ajudou a refletir sobre o trabalho docente nesse segmento, distanciando-nos da ideia que vocação, afetividade e amor pelas crianças são as principais qualidades para exercer a função da docência nessa faixa etária. Os resultados demonstram que, é necessário reafirmar, considerando o contexto econômico e político, a necessidade de investir na formação continuada das docentes da educação infantil, ajudando-as a afastar das formações hegemônicas ligadas aos saberes práticos e tradicionais.
\end{abstract}

Palavras chaves: Trabalho Docente - Trabalho Intelectual - Educação Infantil.

\section{TEACHING WORK IN EARLY CHILDHOOD EDUCATION}

\begin{abstract}
This article looks at what it means to work teaching in early childhood education, linking our theoretical analyses and the challenges presented to this stage of education in the face of the Brazilian conjuncture. We use as instruments for the data collecting readings in the research group, the insertion in the extension course, in dialogue with the coordinators, and the ongoing research in the 28 municipalities of the South of Bahia. The study of early childhood education helped to reflect on teaching work in this segment, distancing us from the
\end{abstract}

\footnotetext{
${ }^{1}$ Doutorado em Educação pela universidade Estadual de Campinas (2011), mestrado em Educação pela Faculdade de Educação da Universidade São Paulo (2001) e graduação em Pedagogia pela Universidade Federal do Espírito Santo (1996). Atua como docente da Universidade Estadual de Santa Cruz, onde integra o quadro permanente do Programa de Pós-Graduação Mestrado Profissional em Educação e coordena o Grupo de Pesquisa Políticas Públicas e Gestão Educacional. É investigadora colaboradora do Centro de Estudos Interdisciplinares em Educação e Desenvolvimento (CeiED/Portugal), compondo o Grupo 1: Educação, Identidades e Políticas Públicas e também coordena o Projeto de Extensão Fortalecimento e Articulação da Educação Infantil/UESC. Tem experiência na área de Educação, com ênfase em Política Educacional, atuando principalmente nos seguintes temas: política educacional e a educação infantil, trabalho docente, formação docente. Desenvolve pesquisa sobre as políticas públicas e condições de trabalho docente na educação básica e superior. E-mail: emilcarl28@hotmail.com

2 Mestrando em Educação em Ciência e Matemática pelo Instituto Federal de Espírito Santo (IFES), Graduado em Física e Química pela Faculté Des Sciences et des Techniques da l'Université Rouen, França (1993). Professor do Ministère de l'Èducation Nationale, França, desde 1994, lecionando as disciplinas de Física e Química no ensino fundamental e médio de 1994 até 2012. Faz parte do grupo de pesquisa Divulgação e Popularização da Ciência do IFES (DIVIPOP). Tem interesse em pesquisa na área de Formação de Professores e na área de Divulgação Científica. Email: frederic.vaillant@hotmail.com
}

RTPS - Rev. Trabalho, Política e Sociedade, Vol. II, no 03, p. 363-374, jul-dez/2017. 
idea that vocation, affection and love for children are the main qualities to exercise the function of teaching in this age group. The results show that it is necessary to reaffirm, considering the economic and political context, the need to invest in continuing training of teachers of early childhood education, helping them stay away from hegemonic formations linked to practical and traditional knowledge.

Keywords: Teaching Work - Intellectual Work - Early Childhood Education.

\section{Introdução}

As discussões aqui apresentadas, sobre o trabalho docente na Educação Infantil, são fruto dos estudos no grupo de pesquisa Políticas Públicas e Gestão Educacional/PPeGE, do Departamento de Ciências da Educação/DCIE, da Universidade Estadual de Santa Cruz/UESC, com alunos/as de graduação de Pedagogia (TCC e IC), mestres e mestrandos em educação e professores das redes municipais de abrangência da UESC e colegas da Universidade.

Estendeu-se para o trabalho no projeto de extensão da Universidade "Fortalecimento e Articulação da Educação Infantil", que além de realizar seminários temáticos sobre essa etapa, promove curso ${ }^{3}$ para coordenadoras pedagógicas da educação infantil. Com a ação extensionista, foi possível elaborar uma pesquisa4 em andamento "Gestão Escolar e o Trabalho Docente na Educação Infantil no Sul da Bahia: desafios e perspectivas", cujo objetivo é analisar as mudanças ocorridas na gestão escolar e no trabalho dos docentes da educação infantil das redes públicas municipais do Sul da Bahia, com o contexto de reformas educacionais implementadas a partir dos anos de 1990.

A inserção nos estudos sobre essa etapa da educação ajudou a refletir sobre o trabalho docente nesse segmento, distanciando-nos da ideia que vocação, afetividade e amor pelas crianças são as principais qualidades para exercer a função da docência nessa faixa etária. Fundamentamos em Gramsci para sustentar que, apesar das suas especificidades, o trabalho docente com crianças pequenas não deixa de ser um trabalho intelectual.

No âmbito dessas ponderações, buscamos analisar o que significa o trabalho docente na educação infantil, ligando nossas análises teóricas aos desafios postos a esta etapa da educação diante da conjuntura política e econômica em que o Brasil se insere na atualidade. Utilizamos como instrumento para coleta de informações as leituras no grupo

\footnotetext{
${ }^{3}$ Em 2017, na terceira edição, o curso “O trabalho da Coordenadora Pedagógica da Educação Infantil”, com 120h, tem objetivo de proporcionar às coordenadoras pedagógicas da EI das redes públicas municipais da área de abrangência da UESC (77 municípios) subsídios teóricos e práticos que propiciem a reflexão sobre seu fazer pedagógico, possibilitando tanto a elaboração quanto o redirecionamento dos projetos educacionais de suas unidades educacionais (Vieira et al, 2016, p. 193).

${ }^{4}$ A pesquisa iniciou em agosto de 2016, com financiamento da Universidade, e é realizada com 28 municípios da região Sul da Bahia. Possui bolsistas do CNPq, da FAPESB e UESC.
} 
de pesquisa, a inserção no curso de extensão, em diálogo ${ }^{5}$ com as coordenadoras, e a pesquisa em andamento nos 28 municípios $^{6}$ do Sul da Bahia.

\section{0 trabalho docente e o trabalho intelectual: o lugar do trabalho docente na educação Infantil}

De acordo com Gramsci, os trabalhadores intelectuais estão, indubitavelmente, vinculados a uma classe social e trabalham a favor dessa classe, intencionalmente ou não. 0 vínculo do intelectual não é, portanto, sua origem social, mas o caráter orgânico que ele desempenha na sociedade. Para Gramsci (1979, p. 08):

Todo homem, fora de sua profissão, desenvolve uma atividade intelectual qualquer, ou seja, é um "filósofo", um artista, um homem de gosto, participa de uma concepção do mundo, possui uma linha consciente de conduta moral, contribui assim, para manter ou para modificar uma concepção do mundo, isto é, para promover novas maneiras de pensar.

Essa citação de Gramsci evidencia que cada indivíduo em menor ou maior grau conhece e participa de uma concepção do mundo imposta pelo ambiente exterior, por vários grupos sociais, nos quais todos estão envolvidos. Retirar-se do mundo externo, é entrar no mundo consciente e elaborar a própria concepção do mundo, de uma maneira crítica e consciente. Dessa maneira, não aceitar o exterior de forma passiva, mas participar ativamente na produção histórica do mundo, sendo guia de si mesmo.

Para mudar esta condição, segundo Gramsci (1978), faz-se necessário fortalecer a si mesmo, desenvolver a si mesmo, uma vez que a atividade para transformar e dirigir conscientemente os homens realiza a sua humanidade, a sua natureza humana. É nessa circunstância que se torna importante o papel do intelectual orgânico na ação contra hegemônica.

0 trabalho dos professores, nesse sentido, é entendido como trabalho intelectual. Carrega consigo, como objeto de trabalho, o conhecimento científico, filosófico e artístico, historicamente construído pela humanidade. Esse conhecimento possui uma dimensão política, na medida em que é compreendido como uma ideologia. Quanto maior a compreensão dessa dimensão, maior a possibilidade de os/as professores/as organizarem

\footnotetext{
${ }^{5}$ No curso utilizamos a metodologia de Pesquisa-Ação, fundamentada nos trabalhos de Thiollent (1985), de Barbier (2007) e na investigação-ação de Paulo Freire (1983). Tal metodologia possibilita uma interação, por meio do diálogo, entre as experiências vividas por nós (coordenadores do curso) nas visitas aos municípios e pelas coordenadoras em suas unidades educativas. Para 2017, estamos trabalhando com 13 municípios e 75 coordenadoras pedagógicas.

${ }^{6} \mathrm{Na}$ aplicação de questionário junto aos professores, coordenadores e gestores dos municípios, dialogamos sobre cada pergunta, numa interação entre pesquisador-sujeito da pesquisa, aproximando da ação-reflexão do seu trabalho docente na Educação Infantil.
} 
o próprio trabalho, a partir de uma determinada orientação política-ideológica (GRAMSCI, 1978).

Isso requer uma autonomia intelectual, o que para Gramsci, não é tão fácil diante da classe dominante. Isso porque esta imprime no intelectual o papel de representante de sua classe, que faria a ligação de suas ideias como se fossem ideias de todos, utilizando o mecanismo persuasivo, pelo consenso, como estratégia dominante.

Segundo Paro (1991), o educador formal, que atua na escola, tem uma dupla responsabilidade no desempenho da função educativa: A primeira delas refere-se à constatação de que a produção do saber só foi possível na medida em que a classe trabalhadora em todos os tempos foi a responsável pela produção material da sociedade, enquanto liberava uma parcela da população para desenvolver o trabalho intelectual. $\mathrm{Na}$ maioria das vezes isso não é nem percebido por esse grupo, acarretando na desigual distribuição social do saber.

A segunda responsabilidade diz respeito à importância que representa para a classe trabalhadora o acesso ao saber para luta pela transformação social. Por tudo isto, diz o autor, os docentes deveriam atuar como um intelectual orgânico da classe trabalhadora, considerando-se inteiramente vinculados a essa classe e aos seus interesses.

$\mathrm{Na}$ medida em que, sem conhecimento objetivo da realidade, não se pode vê-la criticamente, o desenvolvimento de uma consciência crítica na escola deve levar em conta, preliminarmente, a própria valorização dos conhecimentos objetivos que se fazem presentes mesmo no currículo da escola capitalista (PARO, 1991, p. 119).

Nesse aspecto, a educação tem papel importante na reprodução do saber, pois a educação é necessária ao processo de persuasão, justificação e legitimação da hegemonia. No pensamento de Gramsci, não existe a ideia de uma educação neutra, desvinculada da produção ideológica. A manutenção do domínio e do controle na sociedade de classes necessita, constantemente, da reprodução de uma ideologia que dissimule as contradições e as formas de dominação; necessita, portanto, da educação. Ser hegemônica significa remover as contradições das classes na busca pelo poder. Aqui se destaca a especificidade do trabalho docente.

0 trabalho do professor, precisa ser compreendido como característica intrinsecamente humana, que se realiza em condições objetivas e subjetivas. Dessa forma, é preciso entender, segundo Vieira (2008, p. 162), o trabalho dos profissionais da educação, especialmente dos professores, como sujeitos da escola, papel de figura estruturante do grupo, atuante num lugar marcado no tempo e espaço na escola. 0 papel do professor no processo emancipatório da classe "[...] exige no caso dos professores, a necessidade de discriminar ideológica e politicamente, e não somente querer reconhecer 
[...] que a cultura e a educação não são neutros, mas sim o compromisso político e social e tanto educativo e cultural - com as classes subalternas" (MONTOYA, 1991, p. 317).

Dessa maneira, a formação política, como uma ação, é um constante desafio para os professores e deve ser pautada em valores sociais do paradigma humanista, da produção do conhecimento e da produção da cultura, e não centrada na recompensa econômica (VIEIRA, 2008). Nesse contexto, como produzir intelectuais que acima de tudo tenham compreensão histórica do mundo em que vivem da cultura em que estão inseridos, com uma política de formação que prioriza aspectos desvinculados de tais valores?

Como questiona Gramsci, em sua defesa da escola unitária: como organizar a educação de forma a atender a formação humanista concreta e a atividade prática, preparando homens/mulheres para o exercício autônomo e criador de suas funções sociais?

Os professores terão que buscar alterar a conjugação de forças da atual sociedade no que se refere à reprodução da escola enquanto aparelho da sociedade civil. Precisa igualmente encontrar no trabalho coletivo, formas de organização capazes de contraporem-se às atuais condições de produção intelectual hegemônica. Professores/as e crianças que estão na escola pública, necessitam desse lugar como espaço de socialização do conhecimento e produção de consciências capazes de produzirem a transformação social.

0 docente enquanto intelectual tem essa responsabilidade, pois ele não é um mero executor; ele pensa e pode agir diferentemente da hegemonia dominante. 0 trabalho desenvolvido, nesse sentido, torna-se práxis quando permite a reflexão e a elaboração da consciência produzida na realidade vivida, diferenciando-se da natureza. De modo inverso, leva o trabalho do professor a um simples "fazer" que não leva em consideração o "pensar" e "agir" sobre essa realidade, distanciando os docentes de sua práxis no próprio trabalho.

O contexto político e econômico que o Estado capitalista proporciona não possibilita a realização de uma educação comprometida com a transformação social, e nem poderíamos esperar isto, se tratando de uma sociedade estruturalmente desigual. Além disso, o Estado tem também produzido toda ordem de reducionismos e dificuldades no que se refere a dois aspectos, necessariamente interligados: a formação dos docentes (inicial e continuada) e a produção das condições objetivas e subjetivas em que se realiza o magistério.

A ação do Estado no setor educacional tem sido de realizar a difusão da ideologia dominante, contando para tal intento, de manter os docentes como intelectuais de mais baixo nível. Nessa condição, conduz a real subordinação da educação e dos docentes ao modelo hegemônico. Nesse processo, as condições objetivas e subjetivas da organização do trabalho docente também são alvo da ação do Estado e precisam ser pensadas e 
analisadas nesse contexto. Considerando as condições objetivas do trabalho, o que explicita Vieira (2008, p. 162):

[...] as condições objetivas são as condições efetivas do trabalho do professor. Na estrutura física, incluem-se: a adequação do espaço escolar para a atividade profissional; espaço da sala de aula e salas de apoio; salas de professores/as e de produção de material pedagógico; laboratórios; limpeza, higiene e conservação. $\mathrm{Na}$ organização do trabalho docente (tempos e espaços) incluem-se: carga horária; tempo de planejamento coletivo e individual; grupos de estudo; formação continuada; pessoal de apoio; acompanhamento pedagógico. Nos recursos didáticos, incluem-se: material de consumo (papel, tinta, tesoura, lápis, borracha, caderno, fotocópia, material impresso, etc.); material didático (livros de apoio, livros de literatura, retro projetor, data show, computador, etc.).

Dessa maneira, as condições objetivas são compreendidas como os instrumentos de trabalho, os meios utilizados pelos docentes para a objetivação de sua prática. "No cotidiano escolar não podemos desconsiderá-los objetivamente como os meios aos objetivos do trabalho docente, especificamente, e do trabalho escolar em geral" (Vieira, 2008, p. 162).

A realidade, contudo, tem sido perversa quanto a essas condições, ainda, em boa parte das escolas públicas brasileiras. Em se tratando da Educação Infantil, temos vivenciado na região Sul da Bahia, instituições situadas em lugares improvisados e sem condições de uso por parte das crianças já que funcionam em casas pequenas ou galpões. Em relação ao parque e área verde percebemos que com esses modelos de instituições (casas improvisadas), por conta da inadequação do espaço, há o uso da sala de aula como lugar privilegiado para aprendizagem, o que empobrece e transforma o espaço como mais um elemento excludente e desqualificador da educação (GONÇALVES, 1999).

Se se entendemos, como GRAMSCI (1979), que a educação é uma possibilidade de luta por uma nova hegemonia, por uma escola única e humanista, isto significa que precisamos olhar esse espaço e refletir sobre a situação lamentável de manutenção dos prédios escolares; da desconsideração às crianças com necessidades especiais; da rigidez do espaço escolar; de seu autoritarismo, e tentar intervir, até porque temos que pensar quem são os usuários dessa escola pública? Como destaca Gonçalves (1999, p. 31), "daí decorre, então, a possibilidade de atribuir ao espaço escolar construído um significado mais humano capaz de contribuir para a necessária construção de um novo espaço criativo".

Identificamos que as instituições, de acordo com nossas pesquisas, não estão localizadas em lugares de fácil acesso. Muitas salas de referências das crianças não favorecem espaço acolhedor; a interação e nem a autonomia das crianças, já que possuem poucos recursos que favoreçam a livre escolha, a imaginação e encantamento através das cores e texturas. Pensar na contra-hegemonia visa construir um ambiente físico destinado à Educação Infantil, promotor de aventuras, descobertas, criatividade, desafios, aprendizagem e que facilite a interação criança/criança, criança/adulto e deles com o meio 
ambiente. O espaço lúdico infantil deve ser dinâmico, vivo, "brincável", explorável, transformável e acessível para todos (BRASIL, 2006).

Quanto aos recursos didáticos, diferenciamos aqui da estrutura física, mas também compreendidos como meios pelos quais se objetiva o trabalho docente, que em sua especificidade dependem de tais recursos para sua efetivação, como outras profissões dependem de outros meios. Na educação infantil os recursos são fundamentais para o trabalho de autonomia das crianças, e promover interação professora e criança, criança e criança, como momento educativo.

Encontramos em nossas pesquisas objetos e mobiliários dispostos de forma que não atende a autonomia das crianças na hora da manipulação dos brinquedos e dos objetos, dependente à criança de um adulto. Os brinquedos, principal recurso didático, para manipulação das crianças são quase sempre escassos ou vindos de doações, e nem sempre estão em bom estado de uso.

0 reflexo dessas condições objetivas do trabalho docente, é que o professor se priva de tais recursos por ser compreendido como a figura central, grandemente influenciado por uma visão tradicional do ensino, que prioriza a transmissão do conteúdo pelos docentes, descartando a contribuição que tais recursos possam ter. Tal situação tem efeito perverso sobre os docentes, privando-os de melhores condições de trabalho. Quando se fala da Educação Infantil, que exige uma especificidade, os problemas são maiores.

Quanto às condições subjetivas do trabalho docente, consideramos o sentido da ação docente a partir da compreensão do trabalho como função estritamente humana e sua função específica na estrutura social, na sociedade capitalista. De acordo com Vieira (2008, p. 163), a ação docente "envolve o trabalho como característica humana incluindo: o sentido da atividade docente, compreendida a partir do significado do trabalho pedagógico na escola capitalista; intencionalidade da ação educativa; produção do conhecimento como característica humana".

Acrescente às condições subjetivas a socialização profissional, as questões das relações de poder e da autonomia tanto da escola quanto dos docentes (VIEIRA, 2008).

No curso com as docentes da educação infantil identificamos uma forte influência da vocação, do afeto e do amor como matriz estruturante para a continuidade do trabalho nas condições objetivas em que se encontram. Esse posicionamento dificulta a compreensão que o trabalho educativo enquanto racionalidade humana necessita que a atividade tenha intencionalidade e planejamento. 0 trabalho educativo alcança sua finalidade quando cada indivíduo singular se apropria dos elementos culturais produzidos historicamente e coletivamente, necessários a sua formação como ser humano. 
O trabalho educativo, por produzir diretamente o processo de educação e humanização, diferencia-se de outros tipos de educação consideradas indiretas. Por isso que os percursos de escolarização e profissionalização precisam ser considerados na hora de analisar o trabalho docente, particularmente, na educação infantil. Estão incutidas nessa análise as diferenças na formação docente; diferenças na socialização profissional e na formação continuada; a organização do poder no cotidiano escolar: distribuição desigual do poder na escola; autonomia escolar (administrativa e pedagógica); autonomia docente. Tudo isso, faz com que o trabalho educativo do docente se diferencia dos demais trabalhos. Isso nos leva a refletir e a pensar essa realidade em um contexto mais específico.

Como garantir a valorização docente (formação inicial e continuada; plano de carreira; salário) e condições de trabalho as professoras da Educação Infantil? Como analisar o trabalho docente na educação infantil na condição de intelectual na contemporaneidade, com essas condições atuais de trabalho? Como ser intelectual na educação infantil?

\section{Desafios e compromissos que precisam ser (re)elaborados: a formação continuada como caminho possível}

Esses questionamentos nos colocam como desafios e compromissos de como reverter essa realidade posta aos docentes, particularmente, da Educação Infantil. No nosso ponto de vista, a educação continuada em contexto é uma possibilidade de apoio aos docentes para efetivação dessa prática.

Garantir formações continuadas, comprometidas com o trabalho educativo do docente, pode ajudá-lo a afastar-se das formações hegemônicas ligadas aos saberes práticos e tradicionais dos professores, lhes dariam condições de discernir para responder de modo adequado às necessidades de aprendizagens das crianças.

Ampliar o campo de atuação das universidades com práticas de ensino é outro caminho possível, particularmente, via Programa Institucional de Bolsa de Iniciação à Docência/PIBID7 e a Extensão. Essas ações podem estimular e apoiar a criação de pesquisa e assessoria, articulados com os municípios a fim de subsidiar o trabalho dos(as) professores(as) da educação infantil. Estimular a articulação entre pós-graduação, núcleos de pesquisa e cursos de formação para profissionais da educação, de modo a garantir a elaboração de currículos e propostas pedagógicas que incorporem os avanços de

\footnotetext{
7 O Programa Institucional de Bolsa de Iniciação à Docência (PIBID) financiado pela Coordenação de Aperfeiçoamento de Pessoal de Nível Superior (CAPES) é um programa que oferece bolsa para estudantes de cursos de licenciatura plena, para que eles exerçam atividades pedagógicas em escolas públicas de ensino básico, aprimorando sua formação e contribuindo para a melhoria da qualidade dessas escolas. Para que os estudantes sejam acompanhados e orientados, os professores das escolas tornam-se orientadores dessa formação.
} 
pesquisas ligadas ao processo de aprendizagens e às teorias educacionais no atendimento às crianças de 0 (zero) a 5 (cinco) anos e 11 meses. Apoiar e acompanhar a regulamentação da Educação Infantil nos sistemas municipais de educação também garantiria o princípio do direito à educação. Esses são alguns dos compromissos e ações que a universidade, por meio de seu corpo docente, poderia ajudar nesse processo de formação que se estenda, para além de uma formação técnica e mecânica, ao processo de emancipação. Essa prática pode permitir a superar a dicotomia entre teoria e prática.

\section{Contexto político e econômico atual}

Enfrentar essas questões e desafios sobre como posicionar o trabalho docente na educação infantil como um trabalho intelectual, não pode ser sem considerar o contexto político e econômico atual em que o Brasil vive. Não se pode fazer essa defesa sem considerar que a realidade social constitui uma totalidade histórico-concreta e que o trabalho das docentes, no caso da Educação Infantil, é parte dessa totalidade.

Desse modo, é preciso entender a conjuntura atual como a aprovação de emenda constitucional que criou o teto para os gastos públicos, a EC 95/2016, que congela por até 20 anos gastos com saúde, educação e aumentos de servidores. Na educação a perda anual de no mínimo 24 bilhões de reais. Essa medida, de acordo com alguns estudiosos, viola o princípio constitucional e afronta a cláusula pétrea, pois desvincula o investimento em educação (18\% União e 25\% Estados, municípios e DF).

0 congelamento durante 20 anos dos recursos para saúde e educação, particularmente, limita o aumento do crescimento do gasto público à inflação. Diante dessa conjuntura, praticamente inviabiliza as metas e estratégias do PNE/2014, pois provoca significativa perda de recursos.

O PNE (2014-2024) apresentou alguns desafios e estabeleceu algumas metas para colocar em prática ações para Educação Infantil:

Meta 1: universalizar, até 2016, a educação infantil na pré-escola para as crianças de 4 (quatro) a 5 (cinco) anos de idade, e ampliar a oferta em creches, no mínimo, 50\% (cinquenta por cento) das crianças de até 3 (três) anos até o final da vigência deste PNE;

Meta 4: universalizar, para a população de 4 (quatro) e 5 anos, o acesso à educação básica e ao atendimento educacional especializado, preferencialmente na rede regular de ensino;

Meta 6: oferecer educação em tempo integral em, no mínimo, 50\% (cinquenta por cento) das escolas públicas, para atender, pelo menos, $25 \%$ (vinte e cinco por cento) dos alunos (BRASIL, 2014).

Embora as metas estejam relacionadas ao direito à educação, a concretização é dependente dos investimentos na Educação Infantil. Diversas pesquisas (DAVIES, 2008; 
PINTO, 2015; SANTOS, 2016) demonstram que têm sido escassos os recursos, o que prejudica a base estrutural e organizacional para o melhor funcionamento das creches e pré-escolas. Se considerarmos a EC 95/2016, torna-se mais grave, pois além de limitar os gastos com a educação, limita gastos com a valorização do magistério, ao trabalho docente, que está diretamente associado o direito à educação infantil.

Dentro desse contexto, a EC/95 ignora o debate internacional sobre a responsabilização do professor e os resultados recentes de pesquisas sobre a eficácia das dispendiosas políticas de bonificação de professores ("Programa de Certificação Federal Docente"). Distancia-se dos estudos que comprovam a qualidade do ensino não pode ser alcançada sem um esforço de formação dos profissionais da educação e sem melhorar as condições de seu trabalho. Mais que isso, da dependência da melhoria da qualidade da educação ao resultado de um conjunto de ações articuladas, como por exemplo: formação profissional, melhoria do salário do docente e das condições de trabalho.

Além disso, a EC/95 irá inviabilizar a Lei do Piso $^{8} / 2008$, pois proibirá os estados e municípios a corrigir o salário segundo essa lei. Estudo recente de Vieira et alli (2016) evidencia que muitos municípios do Sul da Bahia ainda não pagam o Piso. Sem contar que essa medida contraria o PNE/2014, principalmente o disposto na meta 17, sobre valorizar os/as profissionais do magistério das redes públicas de educação básica de forma a equiparar seu rendimento médio ao dos/as demais profissionais com escolaridade equivalente, até o final do sexto ano de vigência deste Plano.

Pode significar a revogação do PNE/2014, como ocorreu com o PNE de 2001, que foi inviabilizado quando ex-presidente Fernando Henrique Cardoso vetou 9 artigos, todos ligados ao financiamento. De acordo com prof. Dr. Luiz Araújo/UnB "o ganho real acima da inflação não é o único instrumento para aumentar o patamar de valorização”. A valorização também perpassa pela valorização das condições de trabalho. Corre-se o risco de se retornar as creches para área da assistência social, o "Programa Criança Feliz" tem características suficientes para evidenciar essa tendência, assim como, à desprofissionalização docente.

Apesar das contradições nos encaminhamentos das normas legais e políticas de todo o período pós Constituição Federal/1988, marcadas pela luta na correlação de forças, nem de longe, vivíamos um período de regime de exceção. Tempos difíceis e de muita luta!

\footnotetext{
${ }^{8}$ Piso Salarial Profissional Nacional - Lei no 11.738, de 16/7/2008, que instituiu o piso salarial profissional nacional para os profissionais do magistério público da educação básica, regulamentando disposição constitucional (alínea 'e' do inciso III do caput do artigo 60 do Ato das Disposições Constitucionais Transitórias).
} 


\section{Considerações finais}

Nesse texto tentamos evidenciar que o trabalho docente na educação infantil não difere dos outros níveis e modalidades de ensino. 0 trabalho docente na educação infantil é um trabalho intelectual em que se exige um compromisso político e pedagógico para a realização da atividade educativa. Contudo, tem sido um desafio elevar o nível da capacidade intelectual para se distanciar da histórica ideia de que, para ser docente nessa etapa da educação, basta vocação, afetividade e amor, além de contar com atributos que desvia da profissionalização.

\section{Referências}

BARBIER, René. A pesquisa-ação. Tradução de Lucie Didio. Brasília: Liber livro, 2007.

BRASIL. Constituição Federal de 1988. Brasília, DF, 1988. Disponível em: http://www.planalto.gov.br/ccivil_03/constituicao/constituicaocompilado.htm, acesso em 30/08/2017.

. Lei no 9394 de 20 de dezembro de 1996. Estabelece a Lei de Diretrizes e Bases da Educação Nacional. 1996. Diário Oficial da União. Brasília, DF, 1996. Disponível em: http://www.planalto.gov.br/ccivil 03/leis/L9394.htm, acesso em 30/08/2017.

. Lei n ${ }^{\circ} 10.172$ de 09 de janeiro de 2001. Estabelece o Plano Nacional de Educação - PNE. 2001. Diário Oficial da União. Brasília, DF, 2001. Disponível em: http://www.planalto.gov.br/ccivil_03/leis/leis_2001/l10172.htm, acesso em $30 / 08 / 2017$.

Lei n. 11. 738, de 16 de julho de 2008. Regulamenta a alínea "e" do inciso III do caput do art. 60 do Ato das Disposições Constitucionais Transitórias, para instituir o Piso Salarial Profissional Nacional para os profissionais do magistério público da educação básica. Brasília, 2008. Disponivel em: http://www.planalto.gov.br/ccivil 03/ ato20072010/2008/lei/l11738.htm, acesso em 30/08/2017.

. Ministério da Educação. Secretaria de Educação Básica. Parâmetros básicos de infraestrutura para instituições de educação infantil. Brasília: MEC, SEB, 2006. 45 p.

. Lei no 13.005, de 15 de junho de 2014. Aprova o Plano Nacional de Educação e dá outras providências. Diário Oficial da União. Brasília, DF, 2014. Disponível em: http://www.planalto.gov.br/ccivil 03/ ato2011-2014/2014/lei/l13005.htm, acesso em $30 / 08 / 2017$.

. Emenda Constitucional $\mathrm{n}^{\circ}$ 95, de 15 de dezembro de 2016. Altera o Ato das Disposições Constitucionais Transitórias, para instituir o Novo Regime Fiscal. Diário Oficial da União. Brasília, DF, 2016. Disponível em: 
http://www.planalto.gov.br/ccivil_03/constituicao/emendas/emc/emc95.htm, acesso em 30/08/2017.

DAVIES, Nicholas. FUNDEB - A redenção da Educação Básica. São Paulo, Autores Associados, 2008.

FREIRE, Paulo. Pedagogia do Oprimido. Rio de Janeiro Paz e Terra. 1983.

GONÇALVES, Rita de Cássia. A arquitetura escolar como materialidade do direito desigual à educação. Revista Ponto de Vista. v. 1, n. 1, p. 47-57, julho/dezembro de 1999.

GRAMSCI, Antonio. Concepção dialética da História. Rio de Janeiro, Civilização Brasileira, 1978. 1979.

Os intelectuais e a organização da cultura. Rio de Janeiro: Civilização Brasileira,

MONTOYA, Blas Cabrera. El intelectual contra el experto. Sobre la formación y las funciones Del profesorado. Educação \& Sociedade, São Paulo. n. 39, p. 307-324, agosto/1991.

PARO, Vitor. Administração escolar: introdução crítica. 5. ed. São Paulo: Cortez, 1991.

PINTO, José Marcelino R. O FUNDEB na perspectiva do aluno qualidade. Em Aberto. Brasília. v. 28, n. 93. p.101-117, jan./jun.2015.

VIEIRA, Emilia Peixoto. Gramsci e suas contribuições para a compreensão do trabalho docente. Trabalho \& Educação. vol. 17, n. 1, p. 153-165, jan. / abr. - $2008 .$. et alli. A Extensão como Fortalecimento e Articulação da Educação Infantil no Sul da Bahia. In: __. A Educação Infantil em Debate. Curitiba: CRV, 2016. p. 187-200.

SANTOS, Jaedson B. dos. Financiamento da Educação Infantil no FUNDEB. In: VIEIRA, Emilia Peixoto et alli. A educação Infantil em Debate. Curitiba, 2016. p. 27-46.

THIOLLENT, Michel. Metodologia da Pesquisa-ação. São Paulo: Cortez, 1985.

Enviado em 16/08/2017

Aprovado em 06/09/2017 